\title{
DIGITAL ENTREPRENUR OPPORTUNITIES DURNG COVID-19
}

Isaura B Flores, University of North Texas at Dallas, Dallas, TX, U.S.A. Elizabeth Muniz, University of North Texas at Dallas, Dallas, TX. U.S.A.

dx.doi.org/10.18374/IJSM-21-1.2

\begin{abstract}
The COVID-19 pandemic has significantly interrupted universal business operations. As a result, people have engaged in diverse activities to generate extra money to replace lost income. Businesses and organizations have also increased their investment in dynamic channels to survive the pandemic. Consequently, individuals and enterprises have identified the digital economy as a lucrative option to venture during the pandemic. Digital entrepreneurs have increased as people explore ways to generate income online or use their extra time productively. The upsurge in the number of entrepreneurs interested in online prospects has led to the digital economy explosion. Accordingly, digital entrepreneurs have heightened their efforts to exploit emerging opportunities on virtual marketplaces. The digital economy has promising investment prospects, but entrepreneurs need to understand each option's potential to realize maximum gains. Current trends indicate that the digital economy provides profitable alternatives expected to continue beyond the 2020s. In this regard, this research paper aims to examine opportunities for digital entrepreneurs to make money virtually during the pandemic.
\end{abstract}

Keywords: Digital entrepreneur, digital economy, digital services, affiliate marketing, social media advertising, e-commerce, consultancy, day trading, digital economy sustainability 